\title{
Rainfall and Runoff Observations in the Subtropical Forest of Okinawa Island, Japan
}

\author{
Naoki Kabeya ${ }^{*}$, Akira Shimizu1, Takanori Shimizu², Hitoshi Ikuzawa3 ${ }^{3}$, Takuya Arakaki ${ }^{3}$, \\ Hiroshi Furugen", Yashuhiro Ohnuki ${ }^{2}$, Shiho Asano ${ }^{1}$ \\ ${ }^{1}$ Kyushu Research Centre, Forestry and Forest Products Research Institute, Kumamoto, Japan \\ ${ }^{2}$ Forestry and Forest Products Research Institute, Tsukuba, Japan \\ ${ }^{3}$ Okinawa Prefecture Forest Resource Research Centre, Nago, Japan \\ ${ }^{4}$ Incorporated Okinawa Prefecture Environment Science Centre, Urazoe, Japan \\ Email: ${ }^{*}$ kabeya@affrc.go.jp
}

Received 3 February 2014; revised 1 April 2014; accepted 21 April 2014

Copyright (C) 2014 by authors and Scientific Research Publishing Inc.

This work is licensed under the Creative Commons Attribution International License (CC BY).

http://creativecommons.org/licenses/by/4.0/

(c) (i) Open Access

\section{Abstract}

We set up two experimental catchments to provide an improved understanding of hydrological processes in a subtropical forested area in the northern part of Okinawa Island, Japan. We calculated runoff using water level data (recorded by a pressure-type water level gauge installed in a box culvert) and a discharge rating curve (derived from in situ observations). Water balance calculations for 2010 showed that the rainfall, runoff and evapotranspiration losses (= rainfall - runoff) were $3403.6 \mathrm{~mm}, 2285.7 \mathrm{~mm}$ and $1117.4 \mathrm{~mm}$, respectively. This result was in agreement with previous results from other forested experimental catchments in this region. Direct runoff, as a proportion of event total rainfall, can be expressed by the empirical equation $\left(Q_{\text {direct }}=0.0048, P_{\text {event }}\right.$ $\left.1.7971, \mathrm{R}^{2}=0.9599\right)$. When $P_{\text {event }}$ was $100 \mathrm{~mm}$ or less, the ratios of $Q_{\text {direct }}$ to $P_{\text {event }}$ were less than $15 \%$ in general. When $P$ event exceeded $100 \mathrm{~mm}$, the ratios were $20 \%-30 \%$.

\section{Keywords}

Direct Runoff, Forested Watershed, Okinawa Island, Rainfall-Runoff Observation, Sub-Tropical Forest, Water Balance

\section{Introduction}

Hydrologic processes in the humid tropics differ from other regions in that they have greater energy inputs and

\footnotetext{
${ }^{*}$ Corresponding author.
} 
faster rates of change, including human-induced change. Human influences on population growth, land use and climate change will profoundly influence tropical hydrology, but understanding of key hydrologic interactions is limited [1]. Fresh water is one of the most important natural resources, especially on tropical islands. For example, on the tropical island of Zanzibar, Tanzania, tourism has grown rapidly in recent years, and Gössling [2] investigated the causes and consequences of water abstraction by the tourist industry. Their result shows that present levels of withdrawal are not sustainable, and some of the local population is already experiencing water deficits on a daily basis.

Okinawa Island is the largest of the southwestern islands between the East China Sea and Pacific Ocean. The driving force of the island economy is the tourist industry. Because there is a unique culture and history and habitats of precious animals and plants, many tourists visit this subtropical island every year. The water demand of the urban population and tourists has recently increased, and sustainable island tourism is a major issue [3]. Seventy-two percent of the northern part of the island is covered by subtropical forest [4], which is called "Yanbaru" in a regional dialect. There are five dams in the area, Benoki, Fungawa, Aha, Arakawa and Fukuji. These provide fresh water to the central and southern parts of the island, where the main population and industry concentrate [5]. The forestry zone famous for Ryukyu Pine (Pinus luchuensis) is included in this region. The region is also known as a habitat for ecologically significant animals and plants, such as the Okinawa Woodpecker (Sapheopipo noguchii), Okinawa Rail (Gallirallus okinawae) and Ryukyus Islands Tree Rat (Diplothrix legata). Recently, five new species of Clusiidae (Diptera) were discovered in this area [6]. Although there has been much research on biological and ecological aspects, only a few studies have been done on the physical environment of this forest area that provides those species with living environments.

In the 1980-1990s, two experimental forest catchments were established in the central and northern part of Okinawa Island, the Minami-Meijiyama and Hentona. Valuable information about the hydrologic characteristics of an island subtropical forest catchment in Japan was obtained from these catchments [7]. For example, Fujieda et al. [8] calculated water balances from early results in these catchments ("Hedona" described by Fujieda et al. [8] was an incorrect location name; "Hentona" is correct and is used herein). They suggested that annual losses in these catchments were between 900 and $1100 \mathrm{~mm}$ greater than those on the Japanese mainland. Kanna et al. [9] reported water balances for the Hentona catchment over 11 years. They noted that the annual rainfall range of 2076 - $4914.3 \mathrm{~mm}$ was greater than that of annual runoff, and that the ratio of annual runoff to annual rainfall was $56.5 \%$ - $68.9 \%$. The latter two studies included a short-term study of runoff, which continued to be analyzed as a daily unit. Other studies, such as Yoshinaga and Onaga [10], discussed rainfall-runoff observations, but these were treated on an event basis, rather than in the context of annual water balance. There is therefore limited analysis of both short- and long-term rainfall-runoff relationships in forested catchments of the area.

To meet this information need and improve our understanding of hydrologic processes in subtropical forests of Okinawa Island, we established two experimental forested catchments. These catchments were near Mt. Nishime in the northern part of the island. Rainfall and runoff data collection commenced in June 2009. In this study, we report the first year's data. Based on these data, we discuss short- and long-term analyses of rainfall and runoff. These data and analyses will help meet the need for forest hydrological data in the region, and will be indispensable in supporting sustainable and environmental forest management in northern Okinawa Island.

\section{Study Site and Method}

\subsection{Study Site}

The two study catchments, Chibana Nos. 1 and 2, are northwest of Mt. Nishime (peak height $420 \mathrm{~m}$ a.s.l.), Kunigami village in Okinawa Prefecture, Japan (Figure 1). The drainage area of Chibana No. 1 is 36 ha, and that of Chibana No. 2 is 39.5 ha.

The climate is maritime subtropical. At Oku, the location of the nearest AMeDAS data site, $3 \mathrm{~km}$ east-northeast of Chibana No. 1, mean annual air temperature and annual rainfall for 1981-2010 were $20.7^{\circ} \mathrm{C}$ and 2501.5 $\mathrm{mm}$, respectively (data from the Japan Meteorological Agency website). Over this period, maximum air temperature was about $26.5^{\circ} \mathrm{C}$, recorded in August and September. Average minimum air temperature was $14.5^{\circ} \mathrm{C}$, in January and February. Most rain falls in summer, especially in the early summer months of May and June (called "Tsu-yu"), and in late summer or early autumn (August through October) when the island is frequently 


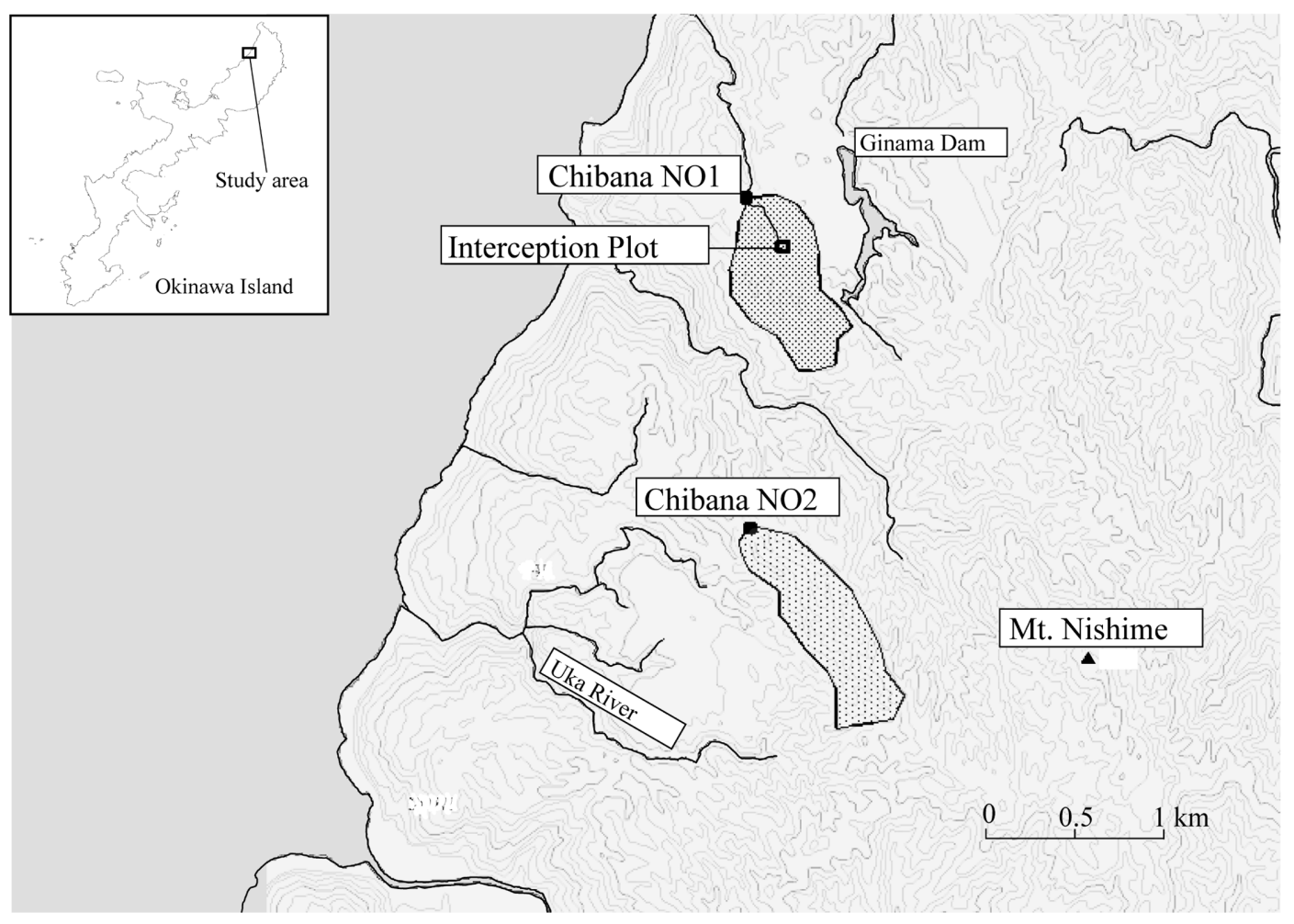

Figure 1. Locations of Chibana No. 1 and No. 2 catchments.

struck by typhoons. Using observed data in this study, annual rainfall in 2010 was $3500 \mathrm{~mm}$. According to previous records (1976-2010) from Oku, this was the third highest value ever recorded. There were many notable rainfall events in 2010, but temperature did not vary much from the 1981-2010 average. The rainfall recorded in February was about 2 - 2.5 times greater than in February of a normal year. This was also the case for May, July, and especially October.

The entire Chibana No. 1 and No. 2 catchments are covered with forest, dominated by planted Pinus luchuensis (Ryukyu Pine). However, invasive species of natural broadleaved evergreen trees (Castanopsis sieboldii, Schima wallichii, Melia azedarach, Cinnamomum camphora) are common. Chibana Nos. 1 and 2 are mainly underlain by sedimentary rocks, such as sandstone and mudstone. Yellow soil is the main soil type.

\subsection{Rainfall and Runoff Measurements}

Rainfall data were gathered by a tipping-bucket automatic recording rain gauge (RG-3M; Onset Computer Corp., Bourne, Massachusetts, USA), installed at the water-level observation point of Chibana No. 1 (Figure 1). Within the Chibana No. 1 catchment, an interception plot (size $5 \mathrm{~m} \times 8 \mathrm{~m}$ ) was established to observe the amount of wet-canopy evaporation [11].

To measure runoff in a small forested catchment, a gauging weir is often used. Although it is possible to obtain very precise measurements with this method, it is expensive to build a structure for exclusive use. Therefore in this study, runoff was observed using a locally constructed civil engineering structure, already in place. Water level was recorded with a prestressed concrete (PC) box culvert. This culvert was designed with a drainage vertical section of $2.5 \mathrm{~m} \times 2.5 \mathrm{~m}$, channel length $\mathrm{L}=18 \mathrm{~m}$, and installation slope $\mathrm{I}=0.001$. The water-level measurement was taken $16 \mathrm{~m}$ from the top of the channel $(\mathrm{L}=16 \mathrm{~m})$. At the bottom of the culvert, a 10 -cm high concrete wall was constructed with the aim of maintaining a residual water level during winter low flow. Thus, the section of flowing water was set into a rectangular double section (Figure 2). Runoff was calculated using rating curves developed from river velocity measured in the field. These velocity measurements were taken under various water-level conditions at each stream water-level observation site. Runoff was determined as discharge divided by drainage area. 


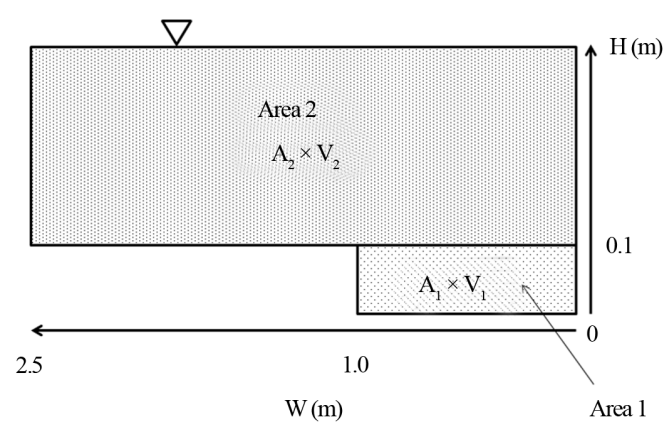

Figure 2. Cross-sections for Chibana No. 1 and No. 2 watersheds.

Water level was observed using a pressure-type water-level gauge (U-20, full scale $4 \mathrm{~m}$; Onset Computer). This type of gauge must be adjusted for barometric pressure. Thus, a water pressure sensor was installed at the bottom of the box culvert at each observation point in Chibana Nos. 1 and 2. A sensor for atmospheric pressure was installed in Chibana No. 1, on the side wall of the box culvert.

The measurement water level, $h(t)$ at time $t$, is shown by the following equation:

$$
h(t)=\left[p_{w}(t)-p_{w}(0)-\left(p_{a}(t)-p_{a}(0)\right)\right] k+h_{0},
$$

where $p_{w}$ is water pressure $(\mathrm{kPa}), p_{a}$ is air pressure $(\mathrm{kPa}), k$ is a unit conversion constant $\left(\mathrm{cm} \mathrm{H}_{2} \mathrm{O} / \mathrm{kPa}\right)$, and $h_{0}$ $(\mathrm{cm})$ is water level at $t=0$. In this study, $k$ was 10.1972 . It was also assumed that the density of river water was constant at $1.0 \mathrm{~g} / \mathrm{cm}^{3}$. We assumed that temporal variation of atmospheric pressure was the same between the two water-level measurement points, so the air pressure data acquired at Chibana No. 1 were also used for water-level calculation at Chibana No. 2. According to the manufacturers, typical error of water-level data collected by the sensors is expected to be within $\pm 0.3 \mathrm{~cm}$. The pressure gauges were tested at constant water level in the laboratory $(h=9.4 \mathrm{~cm})$ before field installation. These tests showed that standard deviations of measurement error were $\pm 0.1-0.18 \mathrm{~cm}$. The pressure gauges recorded at a 10 -min interval, allowing water-level change measurements every $10 \mathrm{~min}$.

Vertical cross-sections of the box culverts at Chibana Nos. 1 and 2 were almost identical, but there was an erosion control dam at Chibana No. 2, $15 \mathrm{~m}$ downstream of the water measurement point. We realized that the observation point was in stagnant water, because the drainage pipe from this erosion control dam was blocked in some rain events [12]. Thus, we used only data from the Chibana No. 1 catchment.

The mean flow velocity was calculated by Manning's equation:

$$
V=n^{-1} R^{2 / 3} I^{1 / 2},
$$

where $V$ is mean flow velocity $(\mathrm{m} / \mathrm{s})$ and $R$ is the hydraulic radius $(m)$. The hydraulic gradient $(I)$ was set to 0.0182 from the plan of the box culvert. Results of the flow velocity measurements for a range of water level conditions were used in Equation (2), and roughness (n) was calculated. Flow velocities were measured by a portable flow current meter (VR-201; KENEK Co. Ltd., Tokyo, Japan). Measurements were taken at the water-level observation points seven times throughout the year (7 January, 15 February, 18 and 25 May, 10 and 27 August, and 27 October 2012), at which times water level $(h)$ was between $2.9-10 \mathrm{~cm}$. To obtain roughness of the entire box culvert, the vertical profile of flow velocity was measured $2 \mathrm{~m}$ upstream where the water was flowing through the entire channel, rather than at a water level measurement section.

\subsection{Analyses of Water Balance and the Rainfall and Runoff Relationship}

Here, runoff $(Q)$ is stream discharge $\left(\mathrm{m}^{3} / \mathrm{s}\right)$ per unit catchment area $\left(\mathrm{m}^{2}\right)$. The units of measurement are mm per $10 \mathrm{~min}$, or per day. The calendar year from 1 January to 31 December 2010 was considered one water year, and annual losses $(L=P-Q)$ and annual discharge rate $(Q / P)$ were calculated from annual rainfall $(P)$ and annual discharge amount $(Q)$.

To analyze the rainfall and runoff relationship, Fujieda et al. [8] and Kanna et al. [9] used a slope-changing 
point method (koubai-kyuhen-ten method in Japanese; [13]). This method used a dataset with daily units to calculate direct runoff amounts. The first step in this method is to make a line for connecting the point at which the slope changed and the point three days after peak runoff in the hydrograph. The area of the hydrograph above this line was then defined as the amount of direct runoff. This method is easy to calculate because the event period is fixed. However, because the method is influenced by catchment complexity, especially its antecedent wetness conditions, runoff will not always return to an initial water level in three days after the rainfall event ends.

Thus, we used higher temporal resolution data (10-min interval data for rainfall and runoff), and direct runoff amounts for each event were calculated by a level abstraction method using the initial runoff amount of a flood. First, the 10-min interval dataset of rainfall and runoff was divided into individual rainfall events. For calculation purposes, the end of the rainfall event was considered when the non-rainfall period had lasted $12 \mathrm{~h}$. Initial runoff was that $10 \mathrm{~min}$ before a rainfall event commenced, and the final runoff after that event was that at which runoff returned to the same value as the initial runoff. We connected these points with a horizontal straight line. The area of the hydrograph above this straight line was deemed the amount $\left(Q_{\text {direct }}\right)$ of direct runoff. Rainfall in this period was termed "event rainfall $\left(P_{\text {event }}\right)$," and the rate $\left(Q_{\text {direct }} / P_{\text {event }}\right)$ of direct runoff was calculated from both ratios. Successive rainfall events sometimes occurred before runoff returned to the level of initial runoff. These cases were unable to be distinguished by our method. However, we analyzed 50 events (events 1 - 50) for which this method was appropriate.

\section{Results}

\subsection{Temporal Variation of Water Level}

The 10-min variation in water level during 2010 in the Chibana No. 1 catchment is shown in Figure 3. Water level during flooding was always less than $50 \mathrm{~cm}$, and that during periods without rain was generally between 0.5 and $5 \mathrm{~cm}$.

The frequency distribution of river water level in the Chibana No. 1 catchment is shown in Figure 4. Most water levels were $10 \mathrm{~cm}$ or less. Maximum, minimum and average water levels were $41.2,2.5$ and $5.9 \mathrm{~cm}$, and the standard deviation was $\pm 3.0 \mathrm{~cm}$. Therefore, we assumed that a discharge rating curve developed from the flow velocity measurements when water level was between 2.9 and $10 \mathrm{~cm}$ would represent the majority of the year.

\subsection{Flow Velocity and Roughness}

Flow velocities $(V)$ over the hydraulic radius $(R)$ (from flow velocity measurements) are shown in Figure 5. Roughness ( $n$ ) was calculated by applying Equation (2) to these data. Values of $V / R$ are large, so roughness (n) is small. The calculated $n=0.0157$ for the vertical profile data obtained from the entire flowing part, $2 \mathrm{~m}$ upstream of water level measurement line. This was similar to the general value for a typical culvert (median value 0.014 , range $0.010-0.020$; [14]). Conversely, the $n$ value of the water level measurement section was calculated at 0.0104 . This smaller value was due to a temporary increase in flow velocity from flow compression in the water level measurement section.

For calculation purposes, the cross-section of the box culvert was described as two simple rectangular double sections (Figure 2). Discharge is equal to the sum total of the flow of the two areas, i.e., area $1\left(A_{1}\right)$ and area 2 $\left(A_{2}\right)$. However, discharge only occurs at $A_{2}$ when water level $(H)$ is 0.10 or more. The mean flow velocities $V$ (m/s) of $A_{1}$ and $A_{2}$ are expressed by Equation (2). Data at the water-level measurement line were used to calculate the roughness of $A_{1}$, considering the compressed flow.

The value calculated from data collected in the entire flowing part was added to the roughness of $A_{2}$. Discharge from the two areas is

$$
Q_{\text {total }}=\left\{\begin{array}{ll}
Q_{1} & \text { at } 0 \leq H<0.1 \\
Q_{1}+Q_{2} & \text { at } 0.1 \leq H
\end{array},\right.
$$

where $Q_{1}=A_{1} \cdot V_{1}$ and $Q_{2}=A_{2} \cdot V_{2}$. Discharge was calculated from the 10-min water-level data using the discharge rating curve. Runoff was calculated by dividing the discharge by catchment area (Figure 6). 


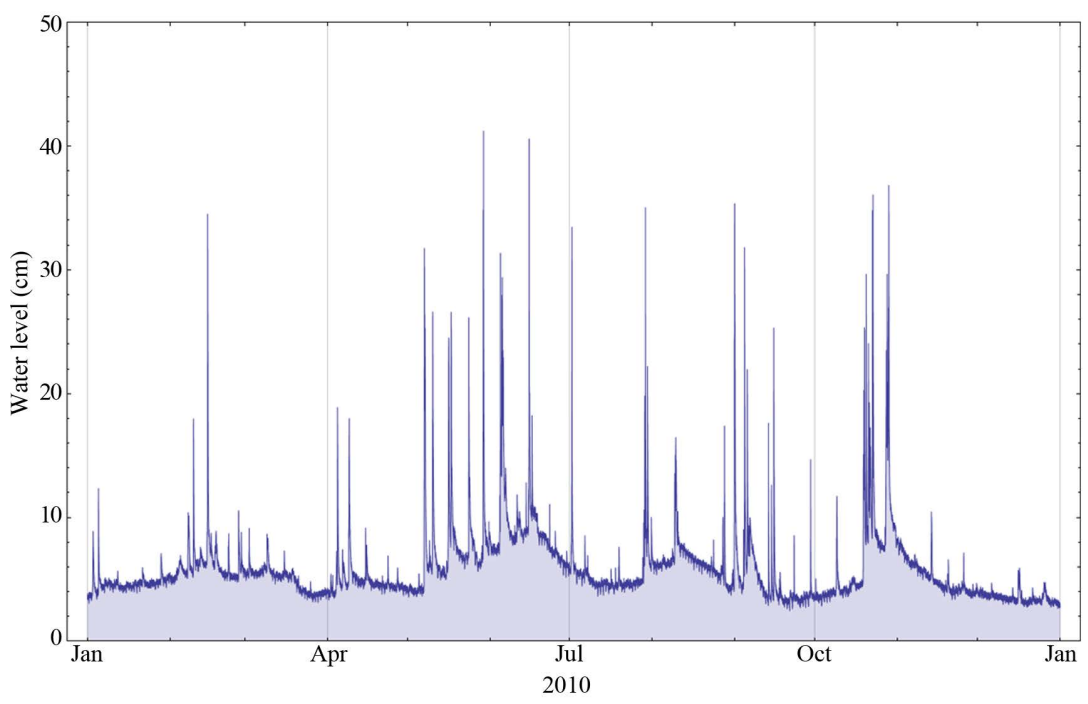

Figure 3. Temporal variation of river water level in Chibana No.1 catchment from 1 January through 31 December 2010 (10-min interval).

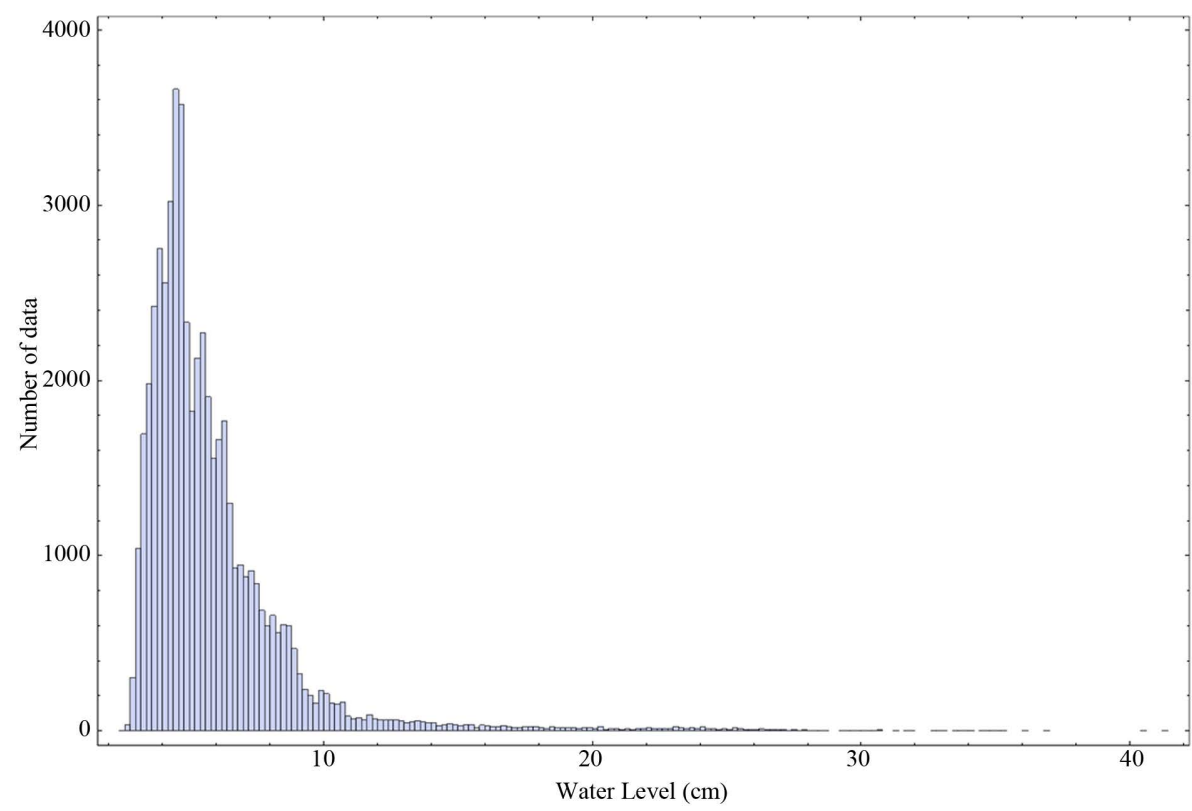

Figure 4. Frequency distribution of river water level in Chibana No. 1 catchment from 1 January through 31 December 2010 (10-min interval; x-axis: water level [cm], y-axis: number of samples).

\section{Discussion}

\subsection{Water Balance}

Annual water balances of forested catchments on Okinawa Island ([8] [9] and the present study) and in southern Kyushu ([15] [16]) are shown in Table 1. Runoff in this table was recorded using a gauging weir in all catchments, except Chibana No. 1 (this study). In the latter catchment, annual runoff was 2285.7 mm and annual rainfall $3403.6 \mathrm{~mm}$, resulting in an annual loss and runoff ratio of $1117.9 \mathrm{~mm}$ and $67.2 \%$. Fujieda et al. [8] reported the water balance of Minami-Meijiyama catchment, where annual rainfall, runoff and loss were 1785.1 mm, $690.9 \mathrm{~mm}$ and $1094.2 \mathrm{~mm}$, respectively. Later, Kanna et al. [9] again reported the water balance of that catchment, with annual rainfall, runoff and loss at $2896.5 \mathrm{~mm}, 1783.3 \mathrm{~mm}$ and $1113.2 \mathrm{~mm}$, respectively. Thus, 


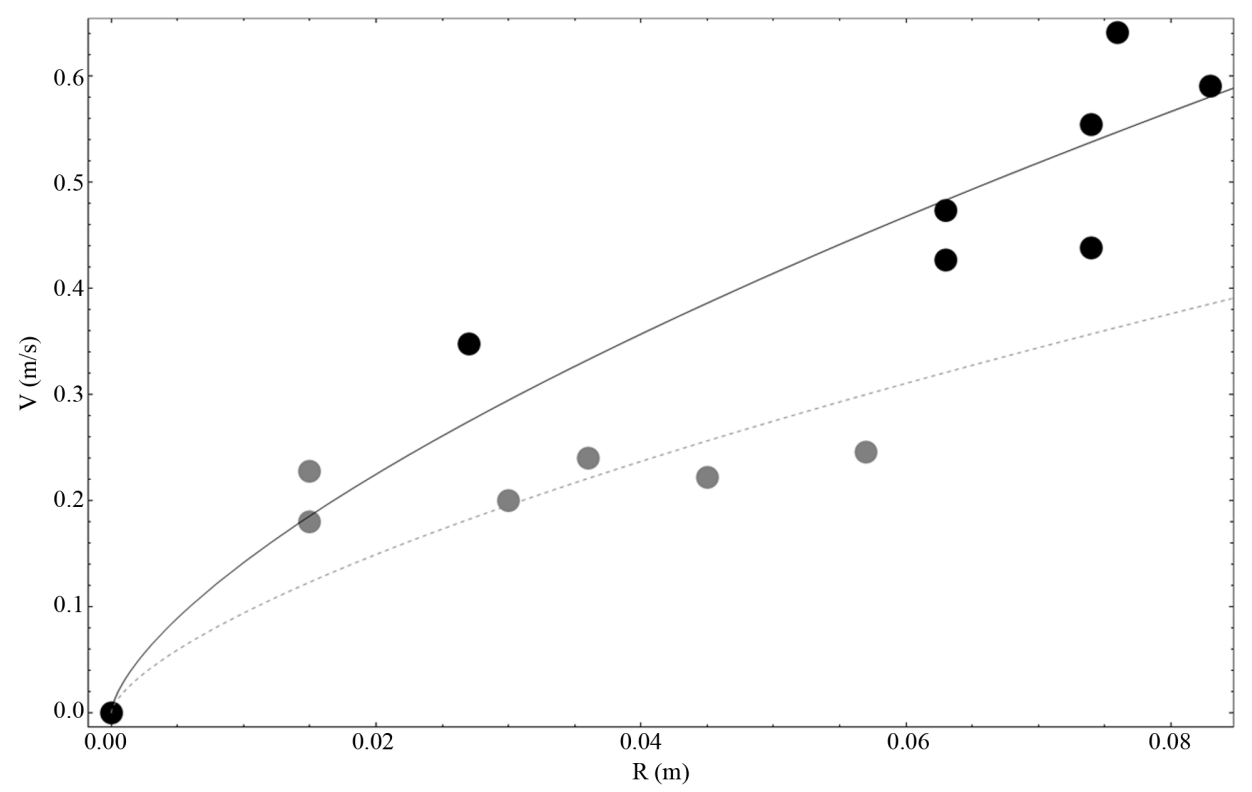

Figure 5. Graph showing flow velocity measurements. Black solid line shows data from water-level monitoring cross-section. Gray dashed line shows data from upper $2 \mathrm{~m}$ where water was flowing through entire channel.
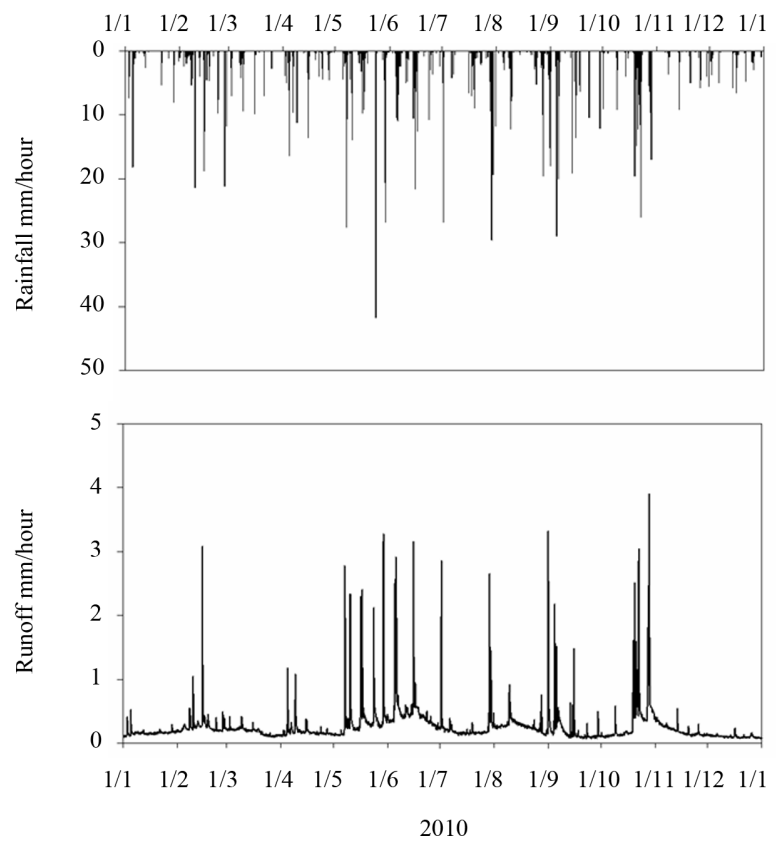

Figure 6. Hyeto-hydrograph of Chibana No. 1 catchment in 2010.

our annual loss of the Chibana No. 1 catchment was nearly the same as values previously reported for other catchments on Okinawa Island. However, annual loss in the Chibana No. 1 catchment was 100 - 200 mm smaller than that in the Sarukawa Experimental Watershed, which has an annual average rainfall of $3000 \mathrm{~mm}$.

Ishijima et al. [4] divided the northern Okinawa region into 108 lattice points, and calculated annual water loss by a bulk method. They found that annual evapotranspiration was $1067 \mathrm{~mm}$ and annual rainfall $2200 \mathrm{~mm}$. Evapotranspiration losses $(P-Q)$ in the Chibana No. 1 catchment were comparable to this regional evapotranspiration value. 


\subsection{Rainfall-Runoff Response}

Relationships between event-total rainfall $\left(P_{\text {event }}\right)$ and amounts of direct runoff $\left(Q_{\text {direct }}\right)$ or direct runoff ratio $\left(Q_{\text {direct }}\right)$ $\left.P_{\text {event }}\right)$ are shown in Figure 7(a) and Figure 7(b), respectively. According to these figures, the amounts of

Table 1. Annual water balance of forested catchments of Okinawa Island and southern Kyushu.

\begin{tabular}{|c|c|c|c|c|c|c|}
\hline & \multirow{2}{*}{$\begin{array}{c}\text { Chibana } \\
\text { No. } 1\end{array}$} & \multirow{2}{*}{ Hentona } & \multirow{2}{*}{$\begin{array}{c}\text { Minami- } \\
\text { Meijiyama }\end{array}$} & \multicolumn{3}{|c|}{ Sarukawa } \\
\hline & & & & No. 1 & No. 2 & No. 3 \\
\hline Annal rainfall $(P) \mathrm{mm}$ & 3403.6 & 2896.5 & 1785 & \multicolumn{3}{|c|}{2997.5} \\
\hline Annal runoff $(Q) \mathrm{mm}$ & 2285.7 & 1783.3 & 691 & 1786.2 & 1700.1 & 1702.5 \\
\hline Annual loss $(P-Q) \mathrm{mm}$ & 1117.9 & 1113.2 & 1094 & 1211.3 & 1297.4 & 1294.9 \\
\hline Runoff ratio $(Q / P) \%$ & 67.2 & 61.6 & 38.7 & 59.6 & 56.7 & 56.8 \\
\hline Reference & This study & [9] & [8] & \multicolumn{3}{|c|}{ [15] and [16] } \\
\hline
\end{tabular}
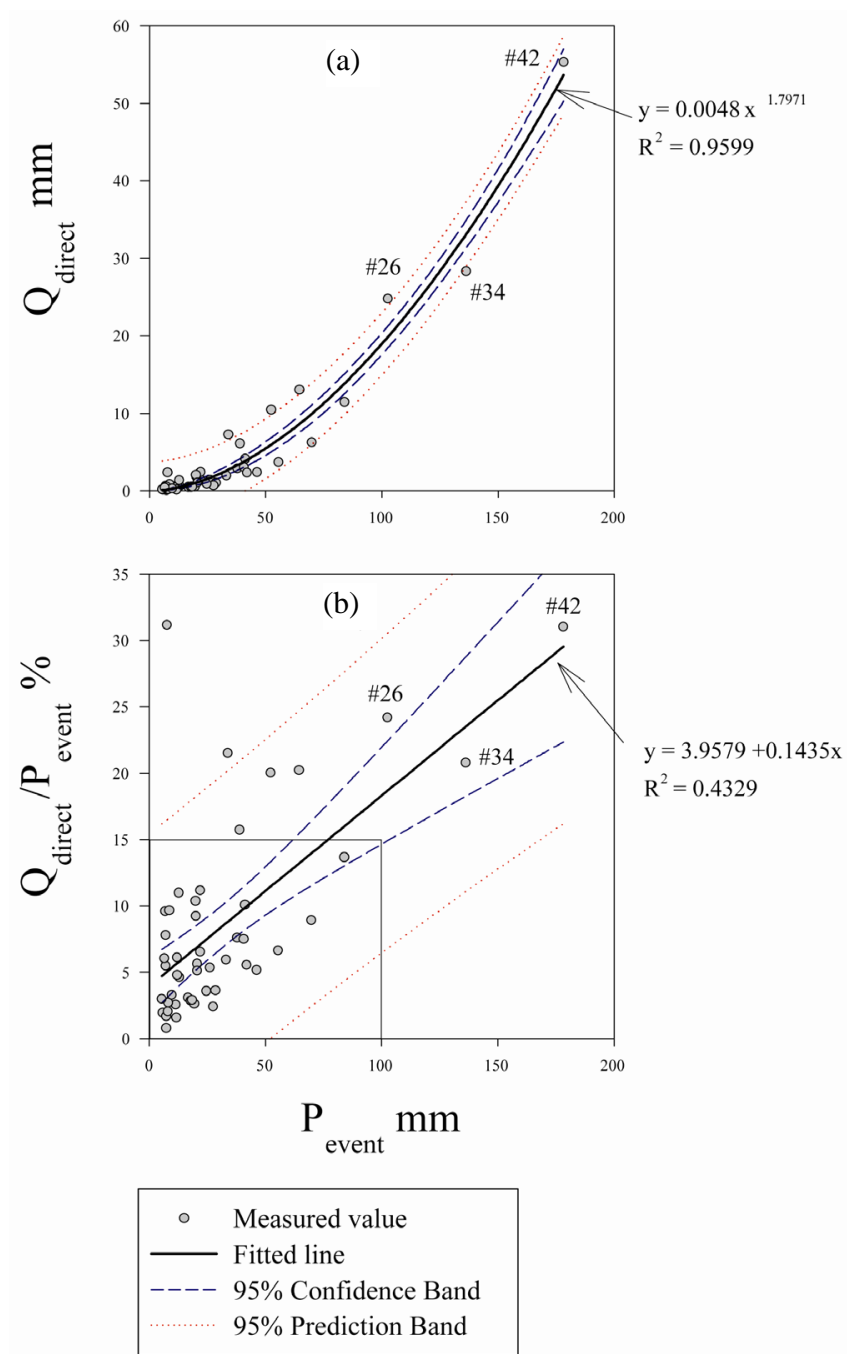

Figure 7. (a) Relationship between event-total rainfall $\left(P_{\text {event }}\right)$ and amount of direct runoff $\left(Q_{\text {direct }}\right)$. (b) Relationships between eventtotal rainfall $\left(P_{\text {event }}\right)$ and runoff ratio $\left(Q_{\text {direct }} / P_{\text {event }}\right)$ for events 26 , 34 and 42. 
direct runoff and the direct runoff ratio increased with event-total rainfall. The amount of direct runoff versus event-total rainfall was able to be expressed by a simple inverse function $\left(Q_{\text {direct }}=0.0048 P_{\text {event }} 1.7971 ; \mathrm{R}^{2}=\right.$ 0.9599), as has been done in other catchments. When total rainfall for an event was $100 \mathrm{~mm}$ or less, the direct runoff ratio to event-total rainfall was generally less than 15\%, although there were some exceptions (in 5 of 47 events). When total rainfall for an event exceeded $100 \mathrm{~mm}$, values of the direct runoff ratio were high, between $20 \%$ and $30 \%$. To put the large events in context, event 26 was the result of a seasonal rain front in June, and events 34 and 42 were during typhoon Nos. 7 (Kompasu) and 14 (Chaba), respectively.

\section{Conclusions}

Two new forested experimental catchments were established to collect information on the water cycle, in a forest in the northern part of Okinawa Island. In one of these, known as Chibana No. 2 catchment, it was difficult to develop a rating curve. This was because the drainage outlet of an erosion control dam was directly under a water level observation point that was frequently blocked during floods, resulting in a temporary stagnant state. In the other catchment, however, known as Chibana No. 1, we acquired 10-min water level data throughout 2010. From these data, we were able to calculate 10-min data of rainfall and runoff. We were therefore able to analyze the water balance and rainfall-runoff response. Although annual rainfall exceeded $3000 \mathrm{~mm}$, losses in the Chibana No. 1 catchment were $1117.9 \mathrm{~mm}$ in 2010, comparable to results from other forested catchments in Okinawa and Kyushu where gauging weirs were used. Thus, we believe that it is possible to establish the water budget of a forest at catchment scale using a low-cost observation technique, with existing infrastructure and a pressure-type water gauge. High-resolution rainfall-discharge data over a year from a forested catchment with rainfall exceeding $3000 \mathrm{~mm}$ were not previously available, but were collected in this study. This study showed a maximum direct runoff ratio of 30\% in rainfall events exceeding $100 \mathrm{~mm}$, as part of the total rainfall produced by a seasonal rain front or typhoons.

In the past, hydrological observations in other study catchments on Okinawa Island (Minami-Meijiyama and Hentona) have been interrupted. This study presents results for one year with heavy rainfall. We obtained a realistic snapshot of the water balance and rainfall-runoff response at catchment scale for that year. By continuing these observations, we will have a better understanding of the hydrologic processes in forested catchments of Okinawa Island.

\section{Acknowledgements}

We thank the staff of the Okinawa Prefecture Forest Resource Research Centre for their help with installation of the field equipment. We would also like to express our thanks to Professor Shigeaki Hattori (President of Aichi Education Centre, the Open University of Japan) for his valuable advice on writing this paper. This study was partly supported by the "Research Project with regard to Environmental Conservation and Resource Utilization of Forest Area in Subtropical Island Region (2008-2010)," funded by Okinawa Prefecture, Japan. A part of this work was done at the Lancaster University under the OECD Co-operative Research Program fellowship 2012. We wish to thank Drs. Nick A Chappell and Wlodek Tych at the Lancaster Environmental Centre of Lancaster University provided us valuable suggestions.

\section{References}

[1] Wohl, E., Barros, A., Brunsell, N., Chappell, N.A., Coe, M., Giambelluca, T., Goldsmith, S., Harmon, R., Hendrickx, J., Juvik, J., McDonnell, J.J. and Ogden, F. (2012) The Hydrology of the Humid Tropics. Nature Climate Change, 2, 655-662.

[2] Gössling, S. (2001) The Consequences of Tourism for Sustainable Water Use on a Tropical Island: Zanzibar, Tanzania. Journal of Environmental Management, 61, 179-191. http://dx.doi.org/10.1006/jema.2000.0403

[3] Kakazu, H. (2011) Sustainable Island Tourism: The Case of Okinawa. In: Carlsen, J. and Butler, R., Eds., Island Tourism: Sustainable Perspectives, CAB International, Wallingford, 171-185. http://dx.doi.org/10.1079/9781845936792.0171

[4] Ishijima, S., Kimura, R., Yokoyama, T., Shimose, R. and Yoshinaga, A. (2000) Observations of the Surface Temperature of the Northern Region of the Okinawa Island with a Preliminary Analysis of Therein Water Balance. Bulletin of the Faculty of Science, University of the Ryukyus, 70, 49-62.

[5] Ito, M. (2010) The Water Resource Development in Okinawa Island. Shimatatei, 53, 14-18. 
[6] Sueyoshi, M., Goto, H., Sato, H., Hattori, T., Kotaka, N. and Saito, K. (2009) Clusiidae (Diptera) from Log Emergence Traps in the Yambaru, a Subtropical Forest of Japan. Entomological Science, 12, 98-106. http://dx.doi.org/10.1111/j.1479-8298.2009.00302.x

[7] Ikuzawa, H. and Kinjyo, M. (1995) Forest Hydrological Catchments in Okinawa. Forest Technology, 644, 13-18.

[8] Fujieda, M., Shimizu, T., Kinjou, M. and Terazono, R. (1995) Hydrologic Environment in Head Areas on Okinawa Island. Journal of Japanese Forest Society, 77, 145-152.

[9] Kanna, K., Arakaki, T. and Kinjyo, M. (2001) Effect of Erosion Control Work on Forest Watershed Conservation-A Case Study of Hydrological Observation at Hentona of Kunigami Village. Bulletin of Okinawa Forest Research Institute, 44, 1-14.

[10] Yoshinaga, A. and Onaga, K. (1993) Effect for Surface Runoff in Small Basin Due to Deforestation. The Science Bulletin of the College of Agriculture, University of Ryukyus, 40, 69-75.

[11] Kabeya, N., Shimizu, A., Shimizu, T., Arakaki, T., Furugen, H., Ikuzawa, H. and Ohnuki, Y. Canopy Interception Bservations in the Northern Forest of Okinawa Island. Kyushu Journal of Forest Research, in Press.

[12] Kabeya, N., Shimizu, A., Shimizu, T., Asano, S., Ikuzawa, H., Imada, M., Higa, M. and Fugugen, H. (2011) Rainfall and Runoff Observations in Forested Watersheds Located in the Sub-Tropic Small Island (II). Kyushu Journal of Forest Research, 64, 105-107.

[13] Japan Society of Hydrology and Water Resources (1997) The Handbook of Hydrology and Water Resources. Asakura Publishing Co. Ltd., Tokyo, 636 p.

[14] Japan Society of Civil Engineers (1985) Hydraulic Formula Book-1985 Editions. Gihodo Shuppan, Tokyo, 625 p.

[15] Shimizu, A., Miyabuchi, Y., Shimizu, T., Ogawa, Y., Daimaru, H., Sato, T. and Takeshita, M. (2008) Statistical Report of Hydrological Observations at the Sarukawa Experimental Watershed (January 1987 to December 2000). Bulletin of Forestry and Forest Products Research Institute, 406, 13-65.

[16] Asano, S., Shimizu, A., Kabeya, N., Hagino, H. and Tamai, K. (2011) Statistical Report of Hydrological Observations at the Sarukawa Experimental Watershed (January, 2001 to December, 2005). Bulletin of Forestry and Forest Products Research Institute, 407, 49-71. 